\title{
LA INVERSIÓN DE IMPACTO, UN MERCADO EN CRECIMIENTO
}

\section{IMPACT INVESTMENT, A GROWING MARKET}

\author{
Jose Luis Ruiz de Munain \\ SpainNAB - Consejo Asesor para la Inversión \\ de Impacto \\ jlruizdemunain@foroimpacto.es
}

\section{RESUMEN}

La adhesión de España al GSG ha supuesto un revulsivo para hacer crecer la inversión de impacto en nuestro país, hasta llegar a una cifra de 2.378 millones de Euros de capital gestionado en 2020. Sin embargo, el mercado aún no cuenta con el volumen y dinamismo que correspondería a un país como el nuestro. El éxito de esta revolución necesita de la involucración activa del Sector Público como ha ocurrido en nuestros países vecinos.

Palabras clave: Inversión de impacto; ODS; Emprendedores sociales; Sector social; Alianzas público-privadas

\section{SUMMARY:}

Spain's adhesion to the GSG has been a catalyst for increasing impact investment in our country, reaching a figure of 2,378 million Euros of managed capital in 2020. However, the market still does not have the volume and dynamism that would correspond to a country like ours. The success of this revolution requires the active involvement of the Public Sector, as has happened in our neighboring countries.

Keywords: Impact investment; SDG; Social entrepreneurs; Social sector; Public-private partnerships

Jose Luis Ruiz de Munain. Licenciado en Ciencias Económicas por la Universidad de Navarra y HEC Lausana (Suiza) y MBA por el IE Business School. Lideró la adhesión de España al Global Steering Group for Impact Investment (GSG), la principal plataforma global para el impulso de la inversión de impacto, y actualmente es Director Ejecutivo de su Consejo Asesor, el SpainNAB. Ha impulsado la creación de LatImpacto, Red de Venture Philanthropy en América Latina, ha trabajado en BID Lab, es Patrono fundador de la Fundación UnLimited Spain y profesor en la temática. 
El mundo se enfrenta a importantes riesgos derivados de la crisis climática y de la pandemia de COVID-19 que amenazan el bienestar, la prosperidad y la vida tal y como la conocemos. A esto se le suma la necesidad de acelerar el ritmo a nivel global para la consecución de los Objetivos de Desarrollo Sostenible (ODS) de la Agenda 2030.

Dar respuesta a estos retos requiere encontrar nuevas fórmulas que permitan sumar capital privado a los recursos públicos y filantrópicos usados hasta la fecha.

En este contexto, la inversión de impacto ha emergido a nivel global como una respuesta innovadora, cada vez más extendida a los retos actuales a los que nos enfrentamos. La inversión de impacto es aquella que busca de forma intencional un impacto social y/o medioambiental positivo medible, además de un retorno financiero.

Pasando del binomio riesgo / rentabilidad al trinomio impacto / riesgo / rentabilidad, perseguimos un cambio histórico en nuestras economías incorporando el impacto en la toma de decisiones económicas y de inversión, en beneficio de las personas y el planeta. La inversión de impacto se convierte así en una herramienta (prácticamente una filosofía) que busca transformar nuestros sistemas económicos en economías de impacto, es decir, economías que sitúan el impacto social y medioambiental en el centro de sus decisiones.

La apuesta por la inversión de impacto es un movimiento global que ha ido ganando peso en todo el mundo. En este sentido, en 2013 el primer ministro británico, David Cameron, elevó la inversión de impacto social a la agenda del G8, creando el G8 Social Impact Investment Task Force, que en 2015 pasa a denominarse Global Steering Group for Impact Investment (GSG), un grupo global independiente que reúne a líderes del mundo de las finanzas, los negocios, la economía social y la filantropía para catalizar el impacto a través de la inversión y el espíritu empresarial para beneficiar a las personas y al planeta. Presidido por Sir Ronald Cohen, considerado el padre de la inversión de impacto, el GSG cuenta en la actualidad con 34 países miembro, además de la Unión Europea.

En 2018, España no formaba parte de este grupo. Conscientes de ello nace la Asociación Foro Impacto quien lideró la adhesión de España al GSG a través de un proceso que involucró a más de 70 organizaciones y personas líderes de la comunidad inversora, empresarial, tercer sector, administraciones y economía social, y que sirvió como espacio de reflexión y puesta en común sobre las principales barreras existentes en España y posibles soluciones para darles respuesta. Las conclusiones se clasificaron en 5 grandes recomendaciones que se recogieron en el documento Hacia una economía de impacto - Recomendaciones para impulsar la inversión de impacto en España.

El proceso culminó en junio de 2019 con la adhesión formal de España al GSG y la constitución del SpainNAB, el Consejo Asesor Nacional para la Inversión de Impacto en España que formado por 16 personas y entidades líderes tiene como misión impulsar y promover la inversión de impacto en España.

Para ello contamos con un Plan de Acción de SpainNAB que gira en torno a 5 recomendaciones: estimular la demanda de capital de impacto a través de alianzas de incubadoras y aceleradoras; incrementar la oferta de inversión con ayuda del Sector Público como catalizador; involucrar en el proceso a las fundaciones; promover contratos de impacto social para impulsar la innovación; y generar conocimiento en torno a estas recomendaciones. Todo ello con el fin último de contar con una estrategia nacional público-privada de Inversión de Impacto, siguiendo el ejemplo de los países miembros del GSG donde los Gobiernos han sido actor clave para catalizar el mercado de Impacto. 
Los logros ya conseguidos pueden medirse en cifras. Si en junio de 2019 partíamos de una cifra de inversión de impacto de 90 millones de euros en activos bajo gestión concentrada en fondos de capital riesgo (VC), en junio de este año 2021 hemos logrado superar con creces el objetivo marcado entonces de multiplicar por cuatro el volumen de este tipo de inversión.

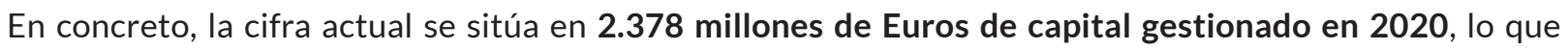
representa un crecimiento del $26 \%$ respecto al año anterior. Estas cifras provienen de un Estudio elaborado por Esade y SpainNAB y publicado en julio de 2021. Este estudio pionero dimensiona y segmenta la oferta de capital de impacto en España considerando un abanico amplio de actores, desde los fondos de capital privado hasta las fundaciones pasando por la banca ética y social. La segmentación basada en las distintas clases de impacto establecidas en el Impact Management Project (IMP), provee la transparencia necesaria para entender en profundidad las diferencias entre el capital de distintos actores que contribuye a solucionar retos específicos sociales y medioambientales.

El alcance de este estudio traspasa nuestro mercado y sirve para liderar la armonización de las cifras de inversión de impacto en otros países europeos en el marco del GSG, con el objetivo de crear un mercado común y reforzar el peso de la inversión de impacto en el espacio UE para avanzar en la creación de una sociedad más justa y resiliente.

Las principales conclusiones son las siguientes:

1. DIVERSIDAD DE MERCADO MÁS ALLÁ DE LOS FONDOS DE CAPITAL PRIVADO: La inversión de impacto va más allá de los fondos de capital privado de impacto (que incluyen fondos de capital riesgo y otros fondos que invierten en el capital de empresas no cotizadas), ya que estos representan únicamente 536 millones de euros, de los 2.378 millones de capital que gestionó el sector en 2020. Aunque estos fondos de impacto han sido pioneros en muchos temas (medición del impacto, incentivos de gestión vinculados al impacto, apoyo financiero a medida en las fases tempranas) y han tomado el liderazgo en los últimos años para impulsar y fortalecer el sector, hay otro tipo de entidades, como la banca ética y social, con una larga trayectoria en el mercado, que gestionan 1.521 millones de euros de capital en inversión de impacto. Esta diversidad de actores, que incluye 242 millones de euros de capital gestionados por fundaciones, hace que la oferta de capital sea variada y pueda atender a las necesidades de financiación de diferentes tipos de empresas y organizaciones

2. RÁPIDO CRECIMIENTO Y GRANDES EXPECTATIVAS: La inversión de impacto es un sector que crece claramente, con una tasa anual del $26 \%$ con respecto a 2019 y que, en el caso de los fondos de capital privado, llega al 34\%. Para 2021, el sector espera también un crecimiento significativo y muchos inversores confían que siga siendo de dos dígitos; además, una tercera parte de los fondos de capital privado espera aumentar el capital gestionado en más del $50 \%$, debido a la ampliación de los fondos actuales y a la creación de nuevos fondos.

3. ADICIONALIDAD EN DISTINTO GRADO: Hemos segmentado el sector en función de la contribución de los inversores a sus objetivos de impacto social y/o medioambiental. Además de la intención de generar impacto, la mayor parte del capital gestionado se dedica activamente a la gestión del impacto, pero no se dirige a mercados de capital nuevos o desabastecidos, ni aporta capital flexible. Esta oferta de capital corresponde, en gran medida, a la banca ética y social. Sin embargo, existe un número importante de vehículos de inversión, entre los cuales destacan los fondos de capital privado, que financian mercados desabastecidos, es decir, que se dirigen a empresas a las cuales les costaría obtener una financiación similar por otras vías. Finalmente, encontramos una serie de fondos de capital privado y de fundaciones que, además de implicarse activamente y dirigirse a mercados desabastecidos, ofrecen capital flexible, asumiendo un riesgo mayor o un retorno financiero inferior al que ofrece el mercado. 
4. MULTIPLICIDAD DE FUENTES Y DESTINOS DE FINANCIACIÓN: La principal fuente de capital para la inversión de impacto son los inversores individuales (69\%), que efectúan su aportación en forma de depósitos y cuentas corrientes a través de la banca ética y social, seguidos de los inversores institucionales (10\%), las fundaciones (10\%) y el sector público (7\%). En el caso de los fondos de capital privado, los inversores principales son los institucionales (29\%), seguidos de las family offices (16\%), los grandes patrimonios (14\%), los fondos públicos nacionales (15\%) y los fondos públicos europeos (9\%). Por tanto, la inversión de impacto es un tipo de inversión que cada vez más actores toman en consideración. El destino de la inversión de impacto también es diverso, en función de la geografía (aunque aproximadamente el $50 \%$ tiene España como su región de referencia) y de la etapa de desarrollo de las empresas financiadas (con preferencia en las fases de crecimiento sobre las de incubación).

5. PLURALIDAD DE INSTRUMENTOS Y EXPECTATIVAS: La mayor parte de la inversión de impacto se canaliza a través de deuda y capital no cotizados (el $75 \%$ y el $25 \%$ respectivamente), con una cierta variación en los retornos esperados (algo mayor en los fondos de capital privado), en el plazo (siendo el más habitual entre 4 y 6 años) y en el tamaño de las inversiones (con un promedio de 1 millón de euros, aunque inferior en la banca ética y social y en las fundaciones).

6. MEDICIÓN DEL IMPACTO CON CAMINO POR RECORRER HACIA LA GESTIÓN DEL IMPACTO: Prácticamente todos los vehículos incluidos en el estudio miden su impacto social. Algunos lo hacen con herramientas estandarizadas (47\%) y otros utilizan solamente herramientas propias (45\%), pero son pocos los actores que llevan a cabo auditorías externas de sus sistemas de medición. Algunos inversores ya utilizan la medición del impacto a lo largo del proceso de inversión, desde la definición de sus objetivos hasta la monitorización y evaluación de sus inversiones. Sin embargo, la gran mayoría utilizan los indicadores de medición de impacto para comunicar los resultados a los diferentes grupos de interés, lo cual indica que todavía hay camino por recorrer para que los inversores pasen de la medición del impacto a la gestión del impacto. Por último, se observa una gran variedad en lo que se refiere a los objetivos de los beneficiarios y a los Objetivos de Desarrollo Sostenible (ODS).

Todas estas conclusiones indican que el mercado no solo ha crecido en cifras, si no también en número y naturaleza de actores. En definitiva, la adhesión de España al GSG y la constitución de SpainNAB ha supuesto un revulsivo para hacer crecer la Inversión y Economía de Impacto en nuestro país.

Desde entonces esta ha ido ganando terreno, con nuevos actores e iniciativas, mayormente privadas. Sin embargo, el mercado aún no cuenta con el volumen y dinamismo que correspondería a un país como el nuestro. El éxito de esta revolución necesita de la involucración activa del Sector Público. Los países de nuestro entorno ya trabajan en ello: Portugal cuenta con Portugal Inovaçao Social, y Francia con Le French Impact, logrando que las administraciones jueguen un rol clave como catalizadoras del capital.

Las alianzas público-privadas y el capital catalítico son factores clave para el desarrollo del mercado de la inversión de impacto. Sin estos elementos, el crecimiento de esta inversión ya sea pública o privada, y por tanto el impacto positivo que se puede generar, será limitado. La crisis actual desatada por la COVID-19 ha puesto de manifiesto la necesidad de invertir a escala para transformar nuestra sociedad y hacerla más resiliente. Es el momento de caminar juntos hacia un nuevo tiempo. 